\title{
Pisando las huellas de Luis Lobera de Ávila: de un Banquete a un Vergel
}

\section{Treading in the footsteps of Luis Lobera de Ávila: from a Banquete to a Vergel}

Andrea Baldissera andrea.baldissera@uniupo.it Università del Piemonte Orientale

Resumen: El estudio pretende establecer las relaciones entre el Banquete de nobles caballeros (1530) y el Vergel de sanidad (1542) de Luis Lobera de Ávila, premisa inesquivable para definir los caracteres textuales de dos importantes documentos en la historia del léxico de la comida hispánica. Se investigan tanto algunos rasgos de la ampliación representada por el Vergel, como las conexiones entre discurso en lengua castellana y glosas marginales en latín.

Palabras clave: Lobera de Ávila, Banquete de nobles caballeros, Vergel de sanidad, refundición, lengua española, latín, filología.

Abstract: The study tries to establish the relationships between the Banquete de nobles caballeros (1530) and the Vergel de Sanidad (1542) by Luis Lobera de Ávila, as inescapable premise to define the textual characters of two important documents in the history of the lexicon of Hispanic food. Both some features of the enlargement represented by the Vergel and the relationships between discourse in Spanish and marginal glosses in Latin are investigated.

Keywords: Lobera de Ávila, Banquete de nobles caballeros, Vergel de sanidad, rewriting, Spanish, Latin, philology.

\footnotetext{
* Este trabajo se inserta en un proyecto de investigación subvencionado por la Università del Piemonte Orientale.
} 
Las obras de Luis Lobera de Ávila, médico de Carlos V, ocupan un lugar destacado tanto en la historia de la medicina española y europea, a comienzos de la Edad Moderna, ${ }^{1}$ como en la de los hábitos alimentarios y de la higiene. ${ }^{2}$ Figuran también en muchas reseñas y repertorios llevados a cabo por estudiosos de la historia del deporte. ${ }^{3}$ De la misma manera, aparecen a menudo mencionadas (pero solo en parte analizadas) en investigaciones sobre la tradición del convite y la cocina en la Europa renacentista (diálogos, tratados). ${ }^{4} \mathrm{La}$ BNE ha incluido a Lobera entre los autores que merecían figurar en la página reservada a la «Gastronomía española: s. XVXVI», ${ }^{5}$ página que brinda una herramienta muy útil: reproducciones de libros antiguos y modernos, referencias bibliográficas, etcétera. Y el proyecto Léxico español de la comida y arte culinario, dirigido por Rolf Eberenz, ahora profesor emérito de la Universidad de Lausana, ha destacado la importancia del médico español, cuyos escritos representan un documento fundamental también para el estudio histórico-lingüístico (por ejemplo, sobre sincronía y diacronía del léxico de ciertos tecnolectos, etcétera). ${ }^{6}$ Cabe precisar, finalmente, que el gran éxito las obras de Lobera de Ávila está atestiguado por los numerosos ejemplares todavía presentes en las bibliotecas del mundo. ${ }^{7}$ Resulta especialmente significativa la difusión del Banquete/Vergel, del que vamos a ocuparnos aquí, que aspiraba a ofrecerse como Galateo de la salud y se inspiraba en las nuevas costumbres cortesanas. ${ }^{8}$

1 La biografía de Lobera de Ávila trazada por Josep Lluís Barona Vilar en la página web de la RAH lleva una abundante bibliografía: destacan en ella Sánchez Granjel (1959) y López Piñero (1983). Podrían añadirse los párrafos reservados a la figura del abulense en Laín Entralgo (1978).

2 Pérez Samper (2004). Subrayan su relevancia en el campo de la higiene individual, por ejemplo, López Piñero (1991) y la tesis doctoral de Jori (2012).

3 Por ejemplo, Vilanou Torrano (2009), Álvarez del Palacio (2009), Torrebadella-Flix (2014).

4Las actas del congreso Codici del gusto, celebrado en Verona en 1991, reúnen varias aportaciones sobre el tema de la comida en el Siglo de Oro que valoran también las obras de Lobera de Ávila. Merecen ser puestas de relieve las ponencias de García Sánchez (1992), Pérez Samper (1992) y Gras i Casanovas (1992). Marras (1992) observa que Cervantes no aprovecha las enseñanzas higiénicas ('caballerescas') de Lobera para don Quijote. No tiene valor científico y plantea erróneamente los aspectos sociológicos, de los tratados del galeno español, el volumen de Herrera Martín (2018).

5 http://www.bne.es/es/Micrositios/Guias/gastronomia/Introduccion/

6 https://people.unil.ch/rolfeberenz/

7 Suficiente será con echar un vistazo a las copias registradas en el Karlsruher Virtueller Katalog para hacerse una idea.

8 Presenta una muestra de la vida señorial en la corte napolitana (con banquetes), el reciente estudio de Hernando Sánchez (2017), que sintetiza muy bien las circunstancias históricas: «Entre estos ocupaba un lugar creciente la educación de los sentidos, el dominio del cuerpo y la salud, que convertirían el banquete en objeto creciente de atención doctrinal, hasta el punto de que algunos Regimientos se llamarán Banquetes o Convites de sanidad. Una de sus máximas expresiones son los tratados del médico Luis Lobera de Ávila, que acompañó a la corte imperial desde 1520 y en 1530 dedicó a Francisco de los Cobos su pionero tratado dietético Banquete de nobles caballeros, reeditado posteriormente como Vergel de Sanidad. Según Lobera, presente en Túnez y Nápoles, "los cavalleros y señores assi de España y de Francia y de Alemaña como de Italia y otras partes usan agora y tienen mucho en costumbre de hazerse

SCRIPTA, Revista internacional de literatura i cultura medieval i moderna, núm. 18 / desembre 2021 / pp. 195-210 ISSN: 2340-4841· doi:10.7203/SCRIPTA.18.22775 
La esencial pero completa biografía, preparada por Josep Lluís Barona Vilar en la página web de la $\mathrm{AH}$, presenta a Lobera de esta forma:

[...] fue uno de los primeros médicos españoles que redactó su obra científica enteramente en castellano. El talante divulgativo y no académico de la misma, destinada a preservar la salud de la clase social dominante, a la que tenía como público destinatario, explica este hecho. ${ }^{9}$

Explica claramente la estrategia editorial del autor: al lado del Regimiento de la salud y de los tratados sobre enfermedades, ${ }^{10}$ se colocan las dos ediciones de una obra que lleva un título mucho más sugerente y literario: el Banquete de nobles caballeros (de 1530), dedicado a Francisco de los Cobos, comendador mayor de León y secretario y del consejo de Estado y secreto de su Majestad, ${ }^{11}$ luego revisado por el mismo Lobera, en 1542, e impreso con el título de Vergel de sanidad. En esta ocasión se inserta en el número de los mecenas (cada uno de los tratados incluidos en el volumen tiene los suyos) a don Pedro de la Cueva comendador de Alcántara y mayordomo de su Majestad.

La príncipe fue publicada en Augusta Vindelicorum (eso es, Augsburgo), y pronto fue traducida al alemán (por Heyrich Steyner, Augsburgo, 1531; ${ }^{12}$ por Christian Egenolff Francfort, 1551, y Egenolphs Erben, Francfort, 1556). Su refundición, en cambio, salió de los tórculos de la imprenta alcalaína de Juan de Brocar. ${ }^{13}$

Ambos libros se presentan como volúmenes facticios, como suma de varios tratados, pero cada uno posee rasgos editoriales y bibliográficos propios, que, además de reflejar la renovada voluntad del autor, enfrentan dos tradiciones tipográficas de la época, bien definidas: la alemana y la española (sobre esto, véase más abajo).

los unos a los otros banquetes y beuer 'autant', que agora dicen...”» (444). Véanse también las atentas observaciones de Álvarez-Ossorio Alvariño (2000: 9-11).

9 https://dbe.rah.es/biografias/19554/luis-lobera-de-avila

10 Libro de pestilencia curativo y preservativo, Alcalá, Juan de Brocar, 1542; Remedio de cuerpos humanos, Toledo, Juan de Ayala, 1544; Libro de las quatro enfermedades cortesanas, Toledo, Juan de Ayala, 1544; Libro del regimiento de la salud, Valladolid, Sebastián Martínez, 1551.

11 La figura del cortesano Franscisco de los Cobos, central en esta época de cambios, está bien retratada en ÁlvarezOssorio Alvariño (2000: 10-11).

12 Esta primera versión, que pertenece al 'catálogo' del mismo impresor del Banquete (Heinrich Steiner), fue estudiada por Dieter Messner (2008).

13 Véanse, al menos, Martín Abad (1991, vol I: el retrato de Juan de Brocar está en las pp. 87-100; la atenta descripción bibliográfica del Vergel de sanidad ocupa las pp. 492-496, núm. 327) y Castillo Gómez (1998). 
Por lo menos hasta donde alcanzo, ${ }^{14}$ parece que al Banquete/Vergel, verdadero resumen del enciclopedismo medieval y renacentista, se han dedicado investigaciones esporádicas e inevitablemente superficiales, que solo han rozado los aspectos macrotextuales de la revisión llevada a cabo por Lobera. Sánchez Granjel notaba que, con respecto al Banquete, en los paratextos del Vergel «se añaden [...] redactadas igualmente en latín, varias dedicatorias y epístolas así como una carta, esta en castellano, de Luis de Lobera al comendador de Alcántara, don Pedro de la Cueva» (1959: 11-12), y precisaba que «la segunda edición ha sido enriquecida con nueve capítulos». Por su parte, Lilao Franco destacaba las novedades del Vergel con respecto al Banquete, resaltando las características de este interesantísimo objeto editorial:

[...] el Vergel se acompaña con el Libro de pestilencia curatiuo y preseruatiuo [...] y con un Remedio de cuerpos bumanos, además de otros tratados menores [...]. Sin embargo, el colofón, con los datos de imprenta, aparece únicamente al final del Remedio [...]. Pero mientras en [la] edición alemana [...] la numeración de los capítulos es consecutiva de los que constituyen el Banquete, en la española se le ha dado entidad propia -ya hemos dicho que con una portada- y los capítulos aparecen numerados del 1 al 15. Lo que sí encontramos en la edición alcalaína son varios capítulos más dedicados a la peste estos redactados en latín (en cursiva, a diferencia de la gótica usada para el castellano), que no aparecían en la edición alemana y que Chinchilla define como un tratadito «reducido à esponer las causas, síntomas, pronóstico y curación de la peste» [.....$^{15}$

Es oportuno hablar también de la faceta tipográfica de las dos obras, y por ello ofrezco a continuación su descripción bibliográfica, precisando que he consultado ejemplares en línea, guardados en la Biblioteca Nacional de España (Madrid, BNE), en la de la Universidad de Sevilla (US) y en la Biblioteca de Cataluña (BCat), entre otros:

1) Vanquete de nobles caualleros e modo de biuir desde que se leuantan hasta que se acuestan; y habla de cada manjar que complexion y propiedad tiene e que daños y prouechos haze, e trata del regimiento curatiuo e preseruatiuo de las fiebres Pestilenciales e de la Pestilencia e otras cosas utilissimas; nueuamente compuesto por el Doctor Luys de Auila; In inclyta Vindelicorum Vrbe Augusta, per industrium virū Henricum Stainerū chalcotypū, [1530?]

$4^{a}[176]$ p. il.

Ejemplares consultados: BNE U/2815; BCat Mar. 74-12

2) Vergel de sanidad: que por otro nombre se llamaua Banquete de caualleros y orden de biuir, ansi

14Debo confesar que no he podido ver las ediciones reprográficas del Banquete, una de las cuales tiene prólogo (Lobera 1952 y Lobera 2012).

15 Lilao Franco (2016).

SCRIPTA, Revista internacional de literatura i cultura medieval i moderna, núm. 18 / desembre 2021 / pp. 195-210 ISSN: 2340-4841· doi:10.7203/SCRIPTA.18.22775 
en tiempo de sanidad como de enfermedad y habla copiosamente de cada manjar que complexion y propiedad tenga y de sus prouechos y daños: con otras cosas vtilissimas / nueuamente corregido y añadido por el mismo autor, que es el doctissimo y excelente doctor Luys Lobera de Auila, medico de su Magestad, Alcala de Henares, en casa de Joan de Brocar, 1542.

Fol. 3 pt. en 1 v. [10], CII h.; [10], XLII h. [= Libro de pestile[n]cia curatituo y preseruatiuo y de fiebres pestilenciales ... compuesto por ... Luys Lobera ... , con portada propia]; [4], CLXXXIII [i.e. CLXXXII $=$ Remedio de cuerpos humanos y silua de experiencias y otras cosas vtilissimas nueuamente compuesto por ... Luys lobera ..., con portada propia], [1] h., [1] en bl.

Ejemplares consultados: BNE U/7990; US A Res.53/5/04

El punto de arranque del tratado fueron las consecuencias de los banquetes, que «minaban» la salud de los cortesanos (según lamentaba también fray Antonio de Guevara en su Aviso de privados y doctrina de cortesanos, capítulo XVIII) ${ }^{16}$ pero la clara intención sociodietética -por así decirlode la primera versión de la obra, bien expresada por el vocablo temático Banquete, en posición inicial (en el título se alude solo de paso a la presencia de asuntos médicos, como las pestilencias etcétera), adquiere una multiplicidad de matices en el fruto tardío y ampliado de 1542. A propósito de ello, Isabel Moyano de Andrés hacía hincapié en la postura de Lobera, capaz de retomar los estudios sobre higiene individual, herederos de los textos medievales, fusionarlos con un proyecto dietético específico y personalizado (el del emperador), en una dimensión heurística renovada, que sobrepasaba los límites de un tratado sobre el bien comer y que tenía «mucho de semilla germinal de la rica corriente de medicina nutricionista que se desarrollaría posteriormente». ${ }^{17}$

El hecho mismo de que, en 1542, Lobera (o bien su editor) proponga un sintagma 'abarcador', marcado por un lexema hiperónimo e inespecífico (Vergel de sanidad), ${ }^{18}$ y que no se centra claramente en la sola faceta de la educación higiénico-alimenticia, parece muy significativo. El título completo (véase arriba) retoma, como es obvio, las fórmulas de 1530, pero adecuándolas a la operación editorial («modo de bivir»> «orden de bivin»; añade luego la precisión «ansí en tiempo de sanidad como de enfermedad») ${ }^{19}$, y, aunque se conserve básicamente el andamiaje de la primera edición, las ampliaciones y la nueva 'cara' de la obra instan a pensar a un público más variado, cortesano o menos que sea, pero perteneciente al grupo social de los caballeros. ${ }^{20}$

\footnotetext{
16 Pérez Samper (2012: 110).
}

17 Moyano de Andrés (2010: 39).

18 A propósito de Vergel, en su Tesoro, Covarrubias (1993) alude al valor sinonímico del término con respecto a jardín, justamente en ámbito librario: «Vergel. También suele llamarse jardín [...] condiciones [...] Ya se han aprovechado deste nombre [= el de jardín] para el frontispicio de algunos libros como jardín de flores, jardín del alma etc.».

19 En las transcripciones modernizo todo rasgo gráfico que no tenga un (posible) valor histórico-fonológico, así como la puntuación, según las normas de la Ortografía RAE de 2010.

20 Se ha hablado de medicina para ricos, a propósito del Banquete, lo que tendría consecuencias temáticas y lingüísticas, 
Según se comentaba, las dos ediciones permiten comparar dos tradiciones editoriales, la alemana y la española. La edición de Alcalá proporciona una especie de viaje en el tiempo hacia atrás, según suele ocurrir con los impresos españoles de esta época: elimina los preciosos y refinados grabados del célebre y desconocido Petrarca-Meister (identificado erróneamente durante mucho tiempo con Hans Weiditz) y de Hans Burkmeir, ${ }^{21}$ y emplea la clásica letra gótica del primer Quinientos español, para el texto principal, en castellano, y la cursiva para las glosas en latín. ${ }^{22}$ En cambio, la alemana proporcionaba ya una perfecta letra redonda renacentista para el texto principal (siendo cursiva la letra del commentus latino). En su análisis de los comentarios humanísticos de inicio siglo, González Vega (1994: 554) aludía a la mayor legibilidad de los tipos góticos para lectores todavía acostumbrados a los manuscritos. En el caso del Vergel (estamos ya en 1542) creo que, además de ser síntoma de cierto tradicionalismo, la elección de Juan de Brocar se funda también en una intencionalidad tipográfico-lingüística: ${ }^{23}$ el tratado bilingüe de Lobera no prevé textos enfrentados y especulares y, en realidad, prima el castellano, mientras que la lengua de Cicerón se perfila como instrumento para las abundantes glosas marginales y come idioma 'bibliográfico', si se me acepta la expresión («la parte llamada propiamente Banquete tiene texto en castellano y en latín, sin que sean exactamente uno traducción del otro»). ${ }^{24}$ Con todo, a veces, la disposición del texto de 1530 (a la izquierda) sugiere casi una dependencia del texto castellano del latino (pese al cuerpo de los caracteres); mientras que la mise en page del Vergel (a la derecha) recuerda la imagen prototípica de la biblia glosada, con el discurso más importante evidenciado por su posición central.

por supuesto (en la «Escusa del auton», que cierra el Vergel, el propio Lobera especifica: «Diome atrevimento a componer la presente obra la natural inclinación que tengo para servir a los cavalleros nobles», fol. CII). Está claro, por otra parte, que no podemos hablar de un libro de bolsillo, para el Vergel, ya que un infolio, en la época, no parecía al alcance de cualquier bolsillo. En cuanto a los precios de los infolios en el XVI, muy útil resulta la información proporcionada por el estudio de Lucía Megías (2008).

21 López Piñero (1987: 36).

22 Para las primeras décadas del siglo aclara la situación el ya clásico estudio de Norton (1997), pero el retraso de la imprenta ibérica, a lo largo de medio siglo por lo menos, ha sido descrito desde varias perspectivas (y con varios matices) por muchos investigadores. Un gran estudioso como Klaus Wagner (1982: 51) explicaba, a propósito de la letrería en la imprenta sevillana: «El fuerte apego a las formas tradicionales representadas por los tipos góticos hace que estos predominen en la mayoría de los libros impresos hasta pasada la primera mitad del siglo XVI, aún cundo, hacia los promedios del siglo, se apunta ya un cambio paulatino en la apreciación estética de los caracteres de imprenta en favor de la letra redonda».

23Juan de Brocar ya tenía explorada la técnica de combinar tipos distinto: en las Obras de Francisco Cervantes de Salazar (glosadas, 1538), reserva para las glosas la redonda y para el texto la gótica. En 1543, en el Aviso de cazadores y de caźa de Pero Núñez de Avendaño, vuelve a una disposición textual análoga a la del Vergel, con la misma alternancia gótica/cursiva.

24Lilao Franco 2016.

SCRIPTA, Revista internacional de literatura i cultura medieval i moderna, núm. 18 / desembre 2021 / pp. 195-210 ISSN: 2340-4841· doi:10.7203/SCRIPTA.18.22775 


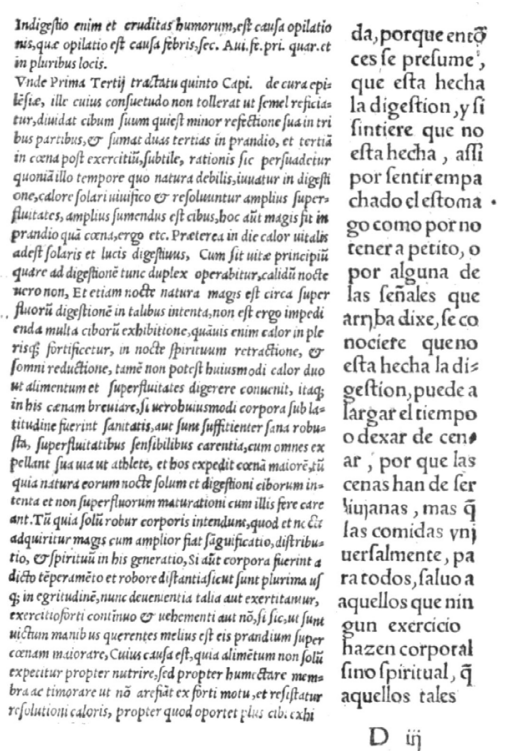

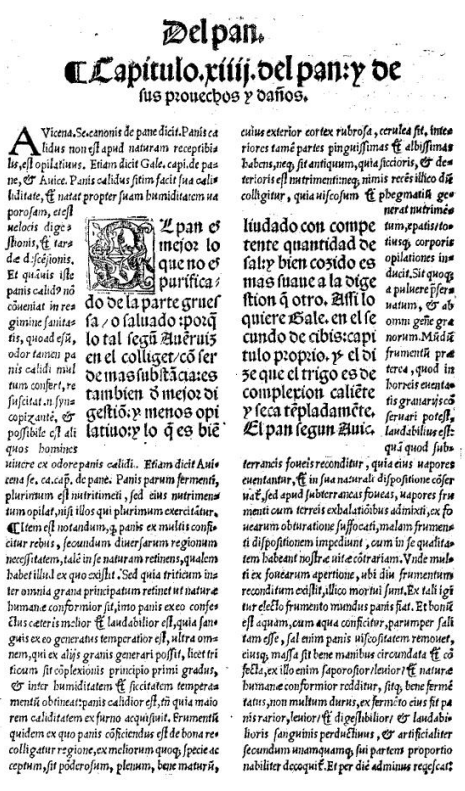

Tampoco la superabundancia del texto latino, que en el Vergel es a menudo consecuencia de las ampliaciones de Lobera, merma el resultado editorial: la diferente maquetación define una nueva jerarquía en el impreso de Juan de Brocar, que, por otra parte, subraya la igual dignidad de la lengua vulgar ya en los pretextos: la dedicatoria a Francisco de los Cobos, aparece en latín y en español; lo mismo ocurre con la epístola de Francisco de Cervantes que presenta la obra al lector. Finalmente, la larguísima carta dirigida al ya mencionado Pedro de la Cueva, en la que el autor explica e ilustra, contestando (ficticiamente) a las preguntas que el mismo Comendador le hizo andando por Francia, Flandes, Alemania, Hungría, Nápoles, Roma, Venecia, Florencia y Milán (según suele ocurrir, la Italia de la época se percibe en su fragmentación política), es un texto en español, una especie de monólogo que 'dialoga' con el lector, un escrito denso y rico en doctrina y en referencias a los auctores clásicos y a los de la tradición médica.

Más allá de las partes añadidas ex novo, ${ }^{25}$ parece esencial estudiar las relaciones entre el discurso castellano y la glosa latina, por un lado - esto nos ayuda a entender cómo iba componiendo su obra el médico imperial-, y la técnica de refundición y ensanchamiento del texto, por el otro. Voy a poner algunos ejemplos, avisando de que a menudo lo que se ve sometido a mayor amplificación es el comentario latino; con todo, hay situaciones y circunstancias bastante variopintas, y no pocos son los párrafos españoles insertados en 1542, lo que tiene gran interés también para la investigación

25 Se trata de unos 20 capítulos, insertados mayoritariamente en la segunda parte de la obra, sobre las propiedades de sendos alimentos, a veces solo mencionados de refilón en 1530: almidón, cebada, moras, canela, garbanzos, etcétera. 
lingüística (léxica, especialmente), ya que se enriquecen justamente secciones centradas en el tema alimenticio-gastronómico. ${ }^{26}$ La fenomenología es variada, tanto en la perspectiva de la amplificatio del texto, como desde la vertiente estilística, según veremos.

1) En el primer ejemplo (más abajo se hallan las imágenes de las dos ediciones) puede observarse la voluntad de dejar ver en transparencia la fuente latina. Transcribo a continuación el paratexto latino, que se asoma de forma más completa y rica en el Vergel (en negrita va la parte añadida, con respecto a 1530):

Dicit Avicenna quod, postquam homo surrexit a somno, debet extendere manus et pedes et alia membra, cuius causa est ut attrahantur vitales spiritus ad membra exteriora. Et propter hoc subtiliantur spiritus cerebri.

Y si nos detenemos en el texto español podemos apreciar la elocutio del autor, quien está traduciendo, según suele hacer de vez en cuando, de forma bastante fiel lo que presentaba el modelo latino, pero en un castellano muy fluyente:

Cuando el hombre se quisiere levantar por la mañana de dormir, ha de estender las manos y los pies y los otros miembros, por que los spíritus vitales se atraigan a los miembros exteriores y se asutilen los spíritus del celebro.
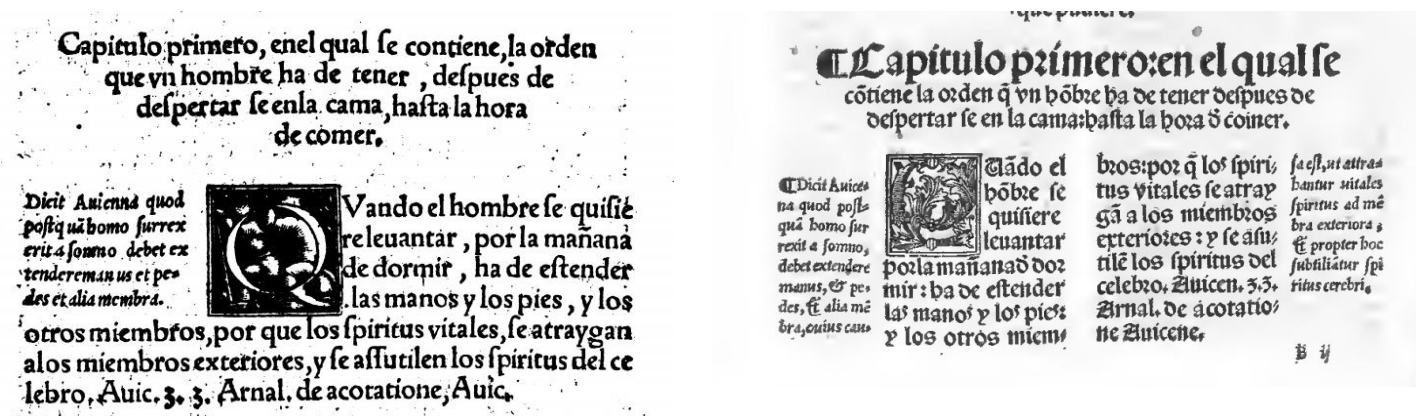

2) En el segundo ejemplo, que procede del prefacio o introducción, en cambio, la distancia textual y lingüística es manifiesta: la elencatio enciclopédica (gastronómica y al mismo tiempo, al menos en parte, zoológica) amplificada en 1542, muy concreta y encaminada a la definición de una conducta y un régimen alimenticios («En un buen banquete ha de haver muchas frutas»; «el banquete no se dize agora bueno si no entra en él pescado», etcétera), convive y se desarrolla en paralelo con el discurso filosófico-científico de la glosa latina, que va moviéndose entre fisiología, patología y ciencia de los alimentos, en un nivel decididamente más abstracto. Se habla de stomachus et virtus

26 En la bibliografía de Eberenz (2018) y en la del proyecto Léxico español de la comida y arte culinario, se hace referencia al solo Banquete. 
retentiva; de splenis et epatis grossitiemi; de nutriens supernutriens o bien -al comienzo- de cibi corrupti vel putrefacti sive carnes, sive pisces, sive fructus [...] semper susceptibiles sunt corruptions et putrefactionis, y así por el estilo. En las reproducciones aparecen enjaulados (gracias a unos rectángulos de color rojo) los pasajes afectados por las integraciones:

\section{VANQVETE DENOBLESCA VALLBROS.}
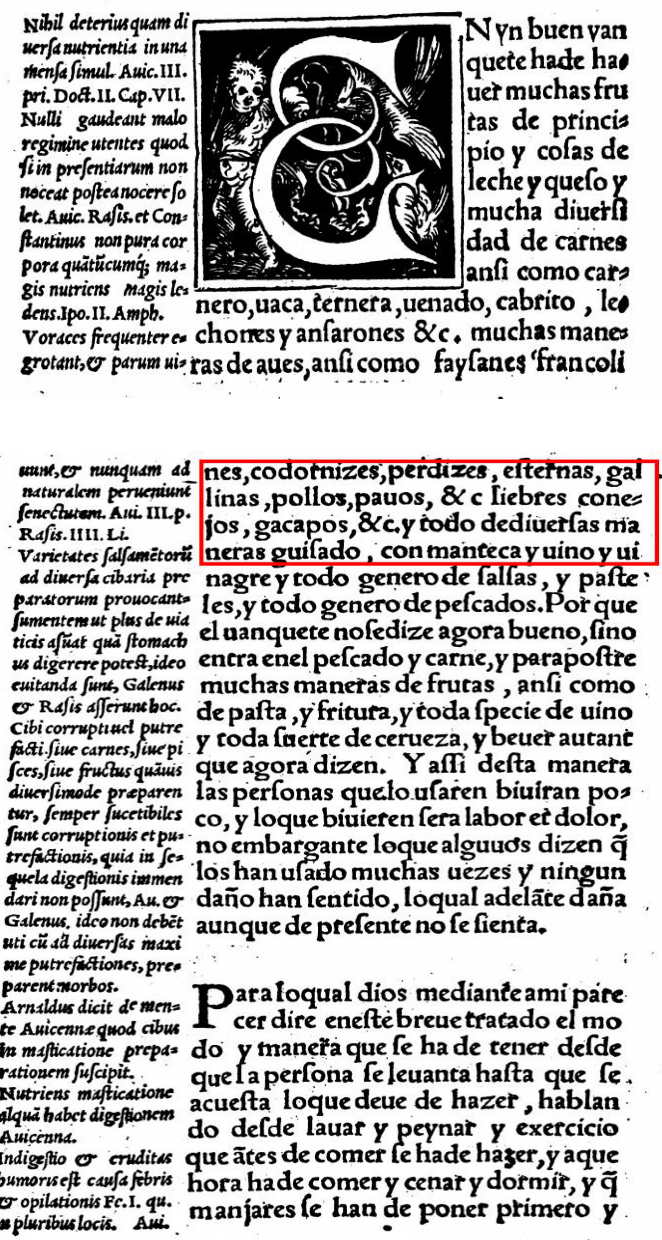

ar Banquete oenobles Eanalleros.
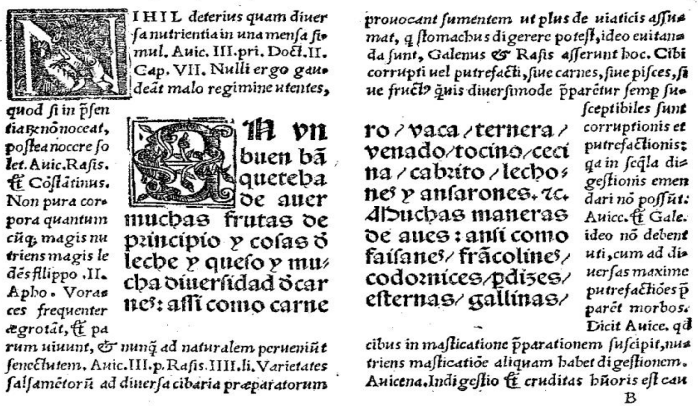

\section{Băquete zo nobles caualleros.}

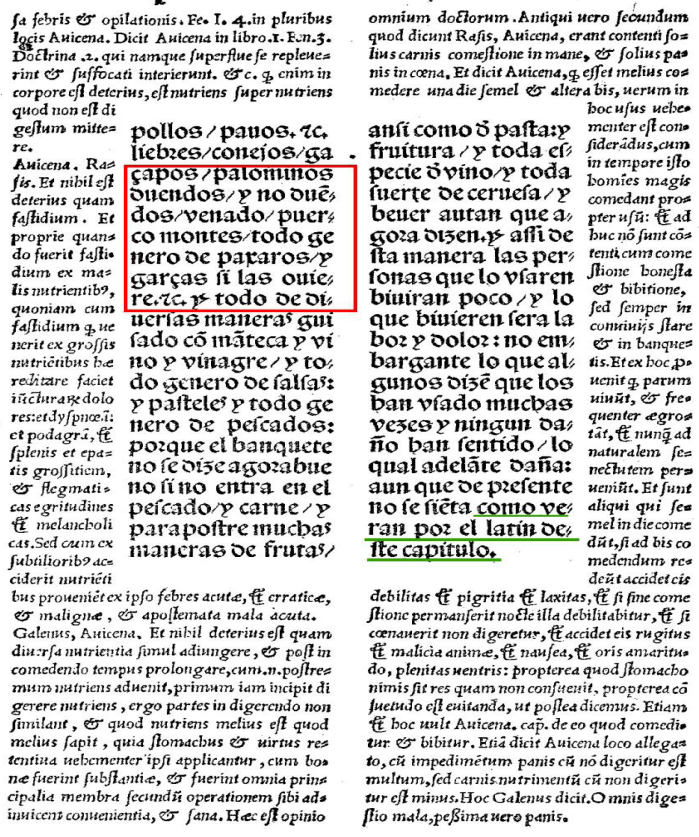

La erudición más pura queda pues en los márgenes, y el lector puede acudir a las columnas impresas en latín para recuperar el saber científico: es bastante frecuente que el mismo Lobera sugiera la posibilidad de profundizar gracias a los materiales 'complementarios' con una breve remisión al texto latino, como para justificar la necesidad de la síntesis en la prosa castellana (en la introducción de 1542, arriba reproducida, puede apreciarse el mecanismo en los últimos renglones, marcados 
en verde: «como verán por el latín deste capítulo»). ${ }^{27} \mathrm{~A}$ veces quiere explicar el cambio de rumbo que ha tomado el discurso en vulgar: en la segunda muestra, el médico imperial quiere brindar una faceta actualizada y práctica (el listado de animales comestibles) ${ }^{28}$ que se contrapone a las (antiguas) teorías médicas que va enumerando y explicando en los espacios marginales, sin que pueda reconocerse una conexión textual directa. Por otra parte, el que no se halle una fuente manifiesta en la inmediata periferia del pasaje no significa que ella no exista: puede que esté en otra sección de la obra (según veremos en el tercer pasaje analizado), o bien, sencillamente, que no haya entrado en el tratado de forma explícita, por ejemplo, porque está escondida detrás de las referencias bibliográficas.

3) La tercera muestra (abajo) procede del solo Vergel (fol. XIIr-XIIIr). En este caso la amplificación es doble: la glosa latina crece sin parar (los segmentos de color azul señalizan, en las imágenes, el punto donde empieza a ampliarse) y, según puede observarse, en el anverso del fol. XII, también se produce un doble marco. El primero está representado por la clásica glosa discursiva; el segundo consiste en palabras clave, que se configuran como palabras clave, o bien como sintéticos resúmenes de largos párrafos (nocumentum somni, de vigiliis, etcétera). Al mismo tiempo el muy breve texto castellano de 1530 va alargándose considerablemente, aprovechando en parte el comentario científico latino, que se vierte al vulgar: las líneas rojas trazadas en las reproducciones evidencian todo lo novedoso, que llega hasta finales del capítulo.

Pero lo más interesante es la traducción (con reelaboración) de una parte del comentario latino que aparece mucho después, subrayado en verde y marcado por la flecha. He aquí los trozos que nos interesan:

Donde se ha de notar que la principio de la noche se eche sobre el lado derecho, porque el hígado se suponga al estómago y le conforte con calor; y en la celebración de la virtud digestiva; y cuando haya passado parte de la noche, ha de bolverse y estar sobre el lado izquierdo, por que el baço haga bien su oficio, que es ampliar los humores engendrados de la superfluidad sanguínea [...] (XIIr-XIIv).

27 Y en el capítulo II, se afirma: «Lo cual verán en latín deste capítulo ad longum y porque es materia de tanta utilidad todo el mundo lo debe exercitar y saber...» (fol Vr). Otro pasaje esclarecedor está en la tabla (Tabula) inicial (fol. ++ IIIIr), donde se anuncia explícitamente que el capítulo XIV («Del pan y de sus provechos y daños») va a exhibir «un tractado muy provechoso en latín de las cualidades y diversidades que hay de panes», un tratado cuyo comienzo se detecta fácilmente gracias a la mayúscula inicial (XXXVIv). En cierta medida tiene razón Solomon (2009), cuando mantiene que «the widespread presence of Latin in this layman-oriented treatise was designed as an indexical device that helped the reader image the physician (...) Rather than distract or discourage the patient, as many vernacular authors believed, the Latin commentary created a visual residue of the physician/author (...) This textual presencing of the physician was designed to comfort and reassure non-professional readers». Pero véase lo que se aclara a propósito del cuarto ejemplo textual, analizado infra.

28Se trata de meras categorías, representadas por sustantivos no contables. En la misma línea, en el capítulo nueve (Del coito, fol, XVIIr), en 1542 Lobera inserta tipologías de vinos añejos («de Pelayos o de San Martín»), que luego se hallan también en el Libro del régimen de la salud (Lobera 1923: 111), publicado en 1551 y donde se reciclan varias ideas debatidas en el Vergel. 
Andrea Baldissera. Pisando las huellas de Luis Lobera de Ávila: de un Banquete a un Vergel

Quidam autem magistri ausserunt buius contrarium, dicunt enim quod decubitus supra dextrum latus iunat ad digestionem, quias tunc epar supponitur stomacho, sicut ignis lebeti [...] Et quia dormiendo supra sinistrum latus perfectius amplectitur, ideo perfectius digerit. Non igitur dormiendum est supra dextrum, nisi parum propter descensum, et deinde supra sinistrum propter digestionem (XIIIr).

Y he aquí las páginas de los impresos:

\section{Delfueño. Foltrij. Lapituloquíntodelfueño oe

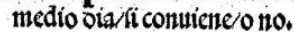

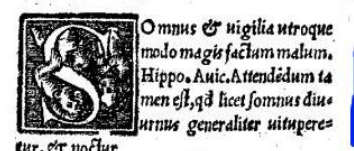

CEft igitur perpendere quanto fomion naturs inuetur. Nam per fomnum calor naturatis qui
oper afur circs materiầnutriméti in interiotibs oper atur circa materiał' hutriméti in interioribs
confortatur, iirquilius uiget alimentidigeflio, en fic melior fit digeflio. Amplius per fomnn̄ tur, or noctur

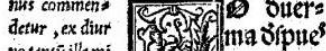

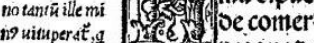
no uituperat, ad tertiam, fci, llo fe figue mucbo licet ab ortu fo daño: afil como go: lisujque ad ter ta/catarro $/ 2$ oolo tia poff ipfum. oe cabeça: y otras iuxta illud Hip mucbas enfermed pocratis prono des y fi vuiere 3002 do dicentis. Sö. mir poz la coftúbze nus ut moris o po: otra cofa:fea ef conueniens media boza oef́pues et naturalis, ut s comer:flota la cin moctem none. ta:p los çapatos à, fugiat, die non tados: 9 cubiertos

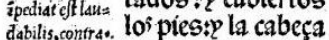
ris uero cft im. alta:? oo:mirpoco: probandus,mi yen lugar obicuro: nus tamen fi a pozque la lübze agí

mane ufque ad
tertia tenuerif:

quanquam tamen fomnus diurnus es meridid nus in tantuma primis medicine innentoribus attefetur; moderno tamen sempore non ommis fornus diurinus eft uituperandus, of proprie fi in co ifle conditiones obferuentur, ut tualt Bar. Prima, quod fit confuetus.sccunda, quod non fitilico jupra cibum. Tertia,quod nor fit cap fiat ab eo fubito funida ef repenting experges fathiofed morofus. ta los buttiozes sy re pia membrace fuelue log fpiritus teriora a fris como vise eatuicena: operationibus, in caplo o opbtbal/" fio fit in quics inia vera:pozque en te, magis tume elvelar oize 2unice, niget digeflio. na que ba oe bauer Amplis $\mathrm{p}$ fom matozerceffo प̄ en el nй uirtutes ans. oozmir efi todo tiê", males quefafi po:mayormére entel gate funt, reto tiempo peftilencial: fortantur: iqui pozô tenemos mas demerant fatio neceffidad o oefecar gate per moa que no oe bumedef, tum, per quies cer. Dondefe ba oe tem fomni for notar que al princis tifcantur. Vins pio oela nocbe fect cbefobze el lado ve cun cepcrit quis gado ie fuponga al quicfere reme quies, niff in fomno.Nâ in rigilis or garnd rens

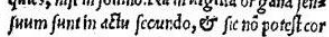
pus vere quiefcre. Vnde etiam membra mosus non ucre quiefcere poffunt in uigitia, propter col ligantiam es propinquitatem ad organta fens fuum qui funt in allu fecundo, ptopter boc igi tur nopotcts bomo effe diu finc formo. Si etim fomnus fuerit moder at9, cibus digcritur et cors pus impinguatur dolor diffoluitur, unimus is fortatur, salor naturalis augmétatur, bumores recbo: pozque d bi dolere, flatim

\section{Capítulo quinto.}
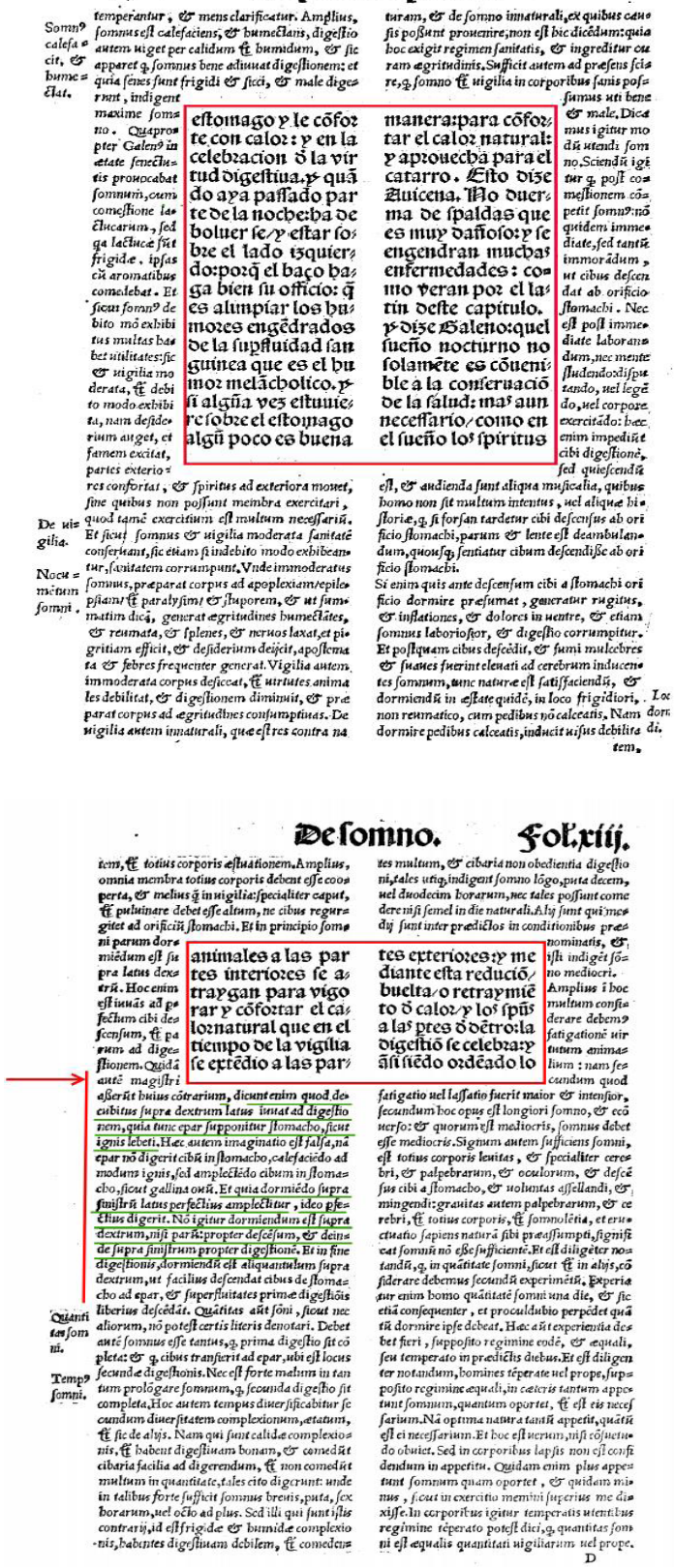
4) El cuarto y último ejemplo viene muy al caso con este número temático de la revista, ya que en el capítulo once se trata de un tema enológico: De vinis reza la cabecera de sección y «De los vinos», la rúbrica. Lobera reformula y completa el rápido final del capitulillo de 1530, apelando también a su experiencia personal, como prueba de la verdad de lo que está afirmando. Lo hace según la mejor tradición 'autóptica' de la literatura ejemplar (yo mismo lo vi, lo oí, lo escuché, etcétera), y, al mismo tiempo, le regala al lector hispanófono una perspectiva contemporánea e internacional de su profesionalidad médica. En negrita resalto el pasaje que justifica la autoridad de Lobera, en cuanto experto:

$[\ldots]$ que en ninguna manera bevan vino dulce que les es muy dañoso, porque los opila. $>[\ldots]$ que en ninguna a manera bevan vino dulce ni mosto que les es muy dañoso, porque el mosto opila el hígado y es ventoso, inflativo y haze mover los humores y otros daños que Galeno y Avicena escriven. Otros muchos vinos hay en España y fuera della de que yo tengo experiencia por haver andado muchas tierras por mar y por tierra; y dado me ha reconoscer algunas cosas que, si no saliera destos reinos, no las pudiera saber, ansí en esto como en otras cosas de la medicina [...].

1530 p. 43

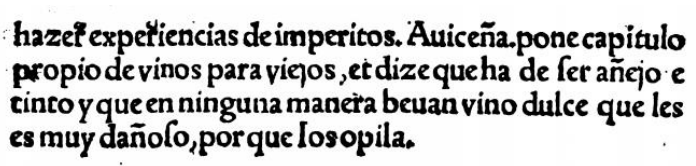

Capirulo XII. dela ceruezay dela płopiedad della y de fus prouechos ydaños,

\section{2 fol. XXIr-v}

Análogo fenómeno ocurre en el éxplicit del capítulo XIII del Vergel («De la calidad y uso del agua»), donde la personalidad del médico se deja escuchar perfectamente: «Esto del agua se note mucho, porque he visto grandes y buenos efectos en fiebres, dándola como conviene y en la cuantidad que 
conviene; $y$ he visto muchos enfermos con solo el bever del agua fría en tiempo, sin otra medicina ninguna, quedar sanos; y por esto le soy aficionado» (XXXVr).

Para concluir, quiero gastar dos palabras sobre algunas facetas lingüísticas, y por consiguiente también filológicas, de las dos ediciones, debidas más a las costumbres de los tipógrafos que a la voluntad del autor. En el Vergel la puntuación padece algunos cambios arcaizantes (como la abundante presencia de los dos puntos, en lugar de la simple coma), y aparecen, de vez en cuando, también formas gráficas menos modernas con respecto a la príncipe (cholérico por colérico; proprio por proprio). También hay errores, de los más típicos de la transmisión textual (pongo solo el ejemplo de una haplografía: «porque de dexarla súbitamente se sigue grand daño», p. $23>$ «porque dexarla súbitamente se sigue grand daño», VIIv); ni faltan los típicos 'embustes' tipográficos, empleados para acortar formas que probablemente no cabían en la pagina (por ejemplo, el adjetivo provechoso se convierte en útil en el fol. XIXr.)

Así que, a una primera hojeada -pero habrá que extender el análisis-, resulta casi más cuidadosamente impreso el texto de 1530 pese a la publicación en tierra extranjera. Pueden imaginarse fácilmente las dificultades lingüísticas para una obra castellana confeccionada en un taller alemán, con todo, los errores son mínimos: paradójicamente, la buena calidad del producto podrá atribuirse justamente a la necesidad de velar con gran atención sobre la forma de un libro alófono, allá por tierras de Baviera, según confiesa el mismo médico imperial en la fe de erratas a finales de la obra:

El que ha compuesto las letras de la impressión deste libro, es mero alemán que no entiende cosa alguna de la lengua latina ni española, por lo cual, aunque se ha tenido mucha vigilancia en la corrección dél, han quedado de lo infinito algunos errores, que por la mayor parte se han hecho por corregir unos, descomponiendo por inadvertencia lo que bien estava, y dexándolo él por que no lo entendía, e yo creyendo que no havía trastrocado la dicción que antes estava bien; pero son muy pocos, según havía aparejo de ser muchos, de los cuales (que más son necessarios) se hará aquí una breve anotación (Banquete, p. 173).

Esta rápida reseña, llevada a cabo desde una perspectiva multidisciplinaria, por muy parcial que sea, ha tratado de ofrecer un primer acercamiento de tipo filológico al Banquete y al Vergel, planteando algunas cuestiones en las que habrá que ahondar más, y de manera pormenorizada, como la relación textual entre dos objetos editoriales (hermanados pero no idénticos), las fuentes, el estilo del autor, etcétera. Con vistas a un estudio más propiamente lingüístico-textual. 


\section{Bibliografía}

Álvarez del Palacio, E. (2009) «Evolución histórica y análisis de los contenidos de la actividad física como forma de salud», en Actividad fisica y salud, Márquez Rosa, S./ Garatachea Vallejo, N. (eds.), Fundiber, Madrid, pp. 15-34.

Álvarez-Ossorio Alvariño, A. (2000) «Introducción», en La corte de Carlos V, Martínez Millán, J. (ed.), vol. 3, tomo 4: Los servidores de las casas reales, Fernández Conti, S. (ed.), Madrid, Sociedad Estatal para la Conmemoración de los Centenarios de Felipe II y Carlos V, pp. 7-42.

Castillo Gómez, A. (1998) «En los comienzos del libro editorial: Apuntes sobre la cultura impresa alcalaína en la primera mitad del siglo XVI», en Congreso internacional sobre Humanismo y Renacimiento, Pérez González, M./Matas Caballero, J. (eds.), León, Universidad de León, 1998, vol. 2 pp. 249266.

Chinchilla, A. (1841-1846) Anales históricos de la medicina en general y biográfico-bibliográficos de la española en particular, Valencia, Imprenta López y Cía., vol. I, pp. 282-303.

Covarrubias, S. de (1993), Tesoro de la lengua castellana o española, Riquer, M. de (ed.), Barcelona, Alta Fulla.

Eberenz, R. (2018) «Discurso y léxico de la alimentación en los tratados médicos medievales y renacentistas», en Actas del X Congreso Internacional de Historia de la Lengua Española, Arnal Purroy, M. ${ }^{a}$ L. / Castañer Martín, R. M. ${ }^{a}$ / Enguita Utrilla, J. Ma . / Lagüéns Gracia, V. / Martín Zorraquino, M. ${ }^{a}$ A., vol. 2, pp. 1075-1088.

Escribano García, V. (1902) La anatomía y los anatomicos españoles del siglo ХИ, Granada, J. López Guevara.

García Sánchez, M. ${ }^{a}$ D. (1992) «Diálogo y convite», en Codici del gusto, Profeti, M. ${ }^{a}$ G. (ed.), pp. 144- 151.

González Vega, F. (1994) «Textos antiguos y comentarios humanísticos en el libro del Renacimiento», en Antonio de Nebrija, Edad Media y Renacimiento, González Iglesias, J. A. / Codoñer Merino, C. (eds.), pp. 549-566.

Gras i Casanovas, M. ${ }^{a}$ M. (1992) «Gusto y alimentación en España: fuentes para su estudio», en

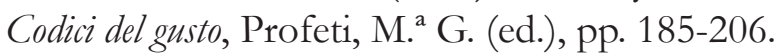

Hernández Morejón, A. (1842) Historia bibliográfica de la medicina española, Madrid, Viuda de Jordán e Hijos.

Hernando Sánchez, C. J. (2017) «El banquete de damas y caballeros», Bulletin hispanique, 119-2, pp. 427-458 https://doi.org/10.4000/bulletinhispanique.5020.

Herrera Martín, A. (2018), Un paseo por la vida cotidiana y la cultura de la alimentación popular en la Edad Moderna (ss. ХИІ-ХИII), de la mano de Luis Lobera de Ávila, s.l. [Almería], Editorial Círculo Rojo.

López Piñero, J. M.a (1983) «Lobera de Ávila, Luis», en Diccionario Histórico de la Ciencia Moderna en

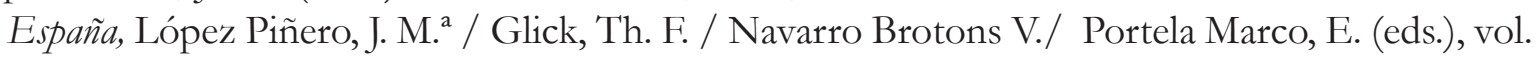
I, Madrid, Península, pp. 529-531. 
Jori, G. (2012) Salud pública e higiene urbana en España durante el siglo XVIII. Una perspectiva geográfica (Universidad de Barcelona), tesis doctoral, Pujadas Rúbies, I. / Capel Sáez, H. (dir. de tesis).

Alberti López, L. (1948) La anatomía y los anatomistas españoles del Renacimiento, Madrid, CSIC.

Lilao Franco, Ó. (2016) La 2. a adenda de Post-incunables ibéricos de Julián Martín Abad y algunos raros impresos conservados en la Biblioteca General Histórica de la Universidad de Salamanca, en http:// bibliotecahistorica.usal.es/es/recursos/historicodenoticias/17-nuestras-colecciones/178-postincunables-2o-adenda (22 julio 2016).

Lobera de Ávila, L. (1923), Libro del régimen de la salud, Madrid, Imprenta y Encuadernación de J. Cosano, Biblioteca Clásica de la Medicina Española, Tomo 5.

Lobera de Ávila, L. (1952) Banquete de nobles Caballeros (1530), prólogo de Juan de Oriol y de La Madrid, Madrid, Reimpresiones Bibliográficas/Talleres Tipográficos Ed. Castilla.

Lobera de Ávila, L. (2012) Vanquete de nobles cavalleros e modo de bivir, A Coruña, Órbigo.

López Piñero, J. M. a (1987) Elgrabado en la ciencia hispánica, Madrid, Consejo Superior de Invetigaciones Científicas.

López Piñero J. M. (1991) El «Vanquete de nombres caballeros» (1530), de Luis Lobera de Avila y la higiene individual del siglo XVI, Madrid, Ministerio de Sanidad y Consumo.

Lucía Megías, J. M. (2008), «Los libros de caballería y la imprenta», en Lucía Megías, J. M. (ed.) Amadis de Gaula 1508. Quinientos años de libros de caballería, Madrid, Sociedad Estatal de Conmemoraciones Culturales (SECC)/ Ministerio de Cultura, Biblioteca Nacional, pp. 95-120.

Marras G. C. (1992), El Vergel de sanidad, ma non per Don Quijote», en Codici del gusto, Profeti, M. ${ }^{a}$ G. (ed.), pp. 207-214.

Martín Abad, J. (1991) La imprenta en Alcalá de Henares: 1502-1600, Madrid, Arco/Libros.

Messner, D. (2008) «Traducir del/al español sin diccionarios en el siglo XVII», Revista de Investigación Lingüistica, 11, pp. 209-222.

Morel D’Areleux A. (1996) «Régimen de sanidad y arte de bien vivir», en Studia áurea. Actas del III Congreso de la AISO, Arellano Ayuso, I. / Pinillos Salvador, C. / Vitse, M. / Serralta, F. (eds.), Pamplona/Toulouse, Universidad de Navarra/Toulouse, vol. 3, pp. 334-346.

Moyano de Andrés, I. (2010) «La cocina escrita», en La cocina en su tinta. Biblioteca Nacional, del 22 de diciembre de 2010 al 13 de marzo de 2011, Adrià i Acosta, F. / Moyano de Andrés, I. / Simón Palmer, M. ${ }^{a}$ del C. (eds.), Madrid, Ministerio de Cultura, pp. 17-59.

Norton, F. J. (1997) La Imprenta en España, 1501-1520, Madrid, Ollero \& Ramos Editores (1.a ed., 1966).

Laín Entralgo, P. (1978) Historia de la medecina, Barcelona, Salvat.

Pérez Samper, M. a de los A. (1992) «Los recetarios de cocina (siglos XV-XVIII)», en Codici del gusto, Profeti, M. ${ }^{a}$ G. (ed.), Milano, Franco Angeli, pp. 152-184. 
Pérez Samper, M. ${ }^{a}$ de los Á. (2004) «La comida escrita en la España del Siglo de Oro», Food \& History, 2-1, pp. 85-136.

Pérez Samper, M. a de los Á. (2012) «Entre la intimidad y la sociabilidad: la alimentación según Fray Antonio de Guevara», Revista de Historia Moderna, 30, pp. 101-122.

Sánchez Granjel, L. (1959) «Luis Lobera de Ávila», Estudios de Historia de la Medicina Española, Nueva serie, 1-4 (y luego en 1967, «Médicos españoles: Luis Lobera de Ávila», Estudios de Historia de la Medicina Española, I, pp. 13-40).

Solomon, M. (2009), «Spectacles of Erudition: Physicians and Vernacular Medical Writing in Early Modern Spain», Digital Proceedings of the Lawrence J. Schoenberg Symposium on Manuscript Studies in the Digital Age, 1, article 6.

Torrebadella-Flix, X. (2014) «El Arte gimnástico-médico. Del humanismo al renacimiento de la educación física en España», Pecia Complutense, 21, pp. 21-45.

Vilanou Torrano, C. (2009) «Higiene, deporte y humanismo en el Renacimiento español», Historia de la educación, 28, pp. 37-59.

Wagner, K. (1982) Martín de Montesdoca y su prensa. Contribución al estudio de la imprenta y de la bibliografía sevillana del siglo ХИI, Sevilla, Universidad de Sevilla. 